\title{
Media Pembelajaran Big Book Berbasis Cerita Rakyat untuk Meningkatkan Karakter Toleransi pada Anak Usia Dini
}

\author{
Yayu Mega Purnamasari ${ }^{\varpi_{1}}$, Wuri Wuryandani ${ }^{2}$ \\ Pendidikan Anak Usia Dini, Universitas Negeri Yogyakarta \\ DOI: $10.31004 /$ obsesi.V4i1.273
}

\begin{abstract}
Abstrak
Karakter toleransi diperlukan bagi setiap individu untuk menciptakan perdamaian di suatu negara. Oleh karena itu karakter toleransi perlu ditanamkan sejak dini agar anak dapat memahami dan menerima setiap perbedaan dari orang lain. Mempelajari karakter toleransi dapat dilakukan melalui berbagai metode salah satunya dengan bercerita menggunakan media big book. Tujuan dari penelitian ini adalah untuk mengetahui efektivitas big book berbasis cerita rakyat dalam meningkatkan karakter toleransi pada anak usia 5-6 tahun. Penelitian ini adalah eksperimen semu dengan pretes-tposttest control group design. Populasi dalam penelitian ini adalah anak-anak berusia 5-6 tahun di Taman kanak-kanak Manonjaya dengan sampel 15 anak dalam kelompok eksperimen dan 15 anak dalam kelompok kontrol. Sampel diambil dengan teknik purposive sampling non-acak. Data dikumpulkan melalui observasi karakter toleransi. Analisis data menggunakan uji homogenitas, uji normalitas, ttest dengan signifikansi tingkat 0,05. Hasil penelitian menunjukkan bahwa media big book berbasis cerita rakyat efektif untuk meningkatkan toleransi karakter anak-anak berusia 5-6 tahun
\end{abstract}

Kata Kunci: buku besar; cerita rakyat; karakter toleransi; anak usia dini

\begin{abstract}
Character of tolerance needs to be instilled early on so that the child can understand and accept every difference from others. Learning character of tolerance can be done through various methods one of them by storytelling using big book media. The purpose of this study is to determine the effectiveness of big book based on folklore in improving the character of tolerance in children aged 5-6 years. This study is a quasi-experiment with pretestposttest control group design. The population in this study were children aged 5-6 years in Manonjaya Kindergarten with a sample of 15 children in the experimental group and 15 children in the control group. The sample was taken by non-random purposive sampling technique. Data were collected through observation of tolerance character. Data analysis using homogeneity test, paired test, and $t$-test, with a significance level of 0.05 . The results showed that the big book media based on folklore is effective to improve the tolerancecharacter of children aged 5-6 years
\end{abstract}

Keywords: big book; folklore; tolerance character; children

Copyright (c) 2019 Ahmad Aly Syukron Aziz Al Mubarok, Amini

$\triangle$ Corresponding author :

Email Address : yayu.mega2016@student.uny.ac.id (Yogyakarta, Indoensia)

Received: 12 August 2019, Accepted: 28 September 2019, Published: 6 October 2019 


\section{PENDAHULUAN}

Dewasa ini, Indonesia tengah mengalami krisis moral, hal ini terjadi seiring berkembangnya zaman yang diakibatkan pengaruh globalisasi dan gaya hidup modern (Noor, 2012). Krisis moral tidak hanya terjadi di lingkungan masyarakat luas tetapi juga dalam lingkungan pendidikan yang ditandai dengan banyak ditemukannya kasus-kasus pada pelajar seperti tawuran, kriminalitas, bullying dan ironisnya hal tersebut juga terjadi pada anak-anak. Data UNESCO 2017 menyebutkan bahwa Indonesia merupakan peringkat tertinggi se ASEAN kasus kekerasan di sekolah yakni sebanyak 84\% diikuti Vietnam 79\%, Nepal 79\%, Kamboja 73\%, dan Pakistan 43\% (https://Republika.co.id). Bullying seringkali disebabkan oleh kurangnya rasa toleransi yang dimiliki seseorang sehingga segala bentuk perbedaan dengan orang lain menjadi sesuatu yang dapat dijadikan bahan ejekan dan memunculkan bullying. Ironisnya Indonesia merupakan negara yang kaya akan kebudayaan, keragaman suku, bahasa dan agama yang mana seharusnya memiliki toleransi yang tinggi.

Permasalahan tersebut perlu mendapat perhatian khusus, agar tidak menimbulkan dampak dikemudian hari, oleh karena itu menanamkan karakter toleransi pada anak sangat diperlukan, (Choen, 2007; Merrow, 2004). Hal tersebut bertujuan agar anak dapat memahami perbedaan dirinya dengan orang lain (Killen, Rutland, \& Ruck, 2011). Toleransi berarti menghormati segala bentuk perbedan baik fisik maupun kepercayaan oang lain (Baklashova, 2015). Dalam hal ini bukan hanya antar individu, toleransi juga merupakan kebijakan sosial diantara orang-orang dan kelompok dengan fisik, dan gaya hidup yang berbeda (Pourghaz, 2016). Selain itu toleransi juga sering diartikan dengan rasa hormat, penerimaan dan apresiasi terhadap keragaman budaya dunia, berbagai ekspresi diri dan cara-cara menjadi manusia, hal ini didorong oleh pengetahuan, keterbukaan, komunikasi dan kebebasan berpikir, hati nurani dan keyakinan dalam hal ini toleransi juga berarti kerukunan dalam perbedaan. Sebuah studi yang dilakukan oleh (Cieri et al., 2014) bahwa toleransi sangat diperlukan untuk transmisi budaya yang efektif serta aspek penting lain dari perilaku manusia lainnya. Toleransi juga merupakan salah satu faktor penting dari adaptasi komunikasi antar budaya (Novikova \& Novikov, 2013)

Toleransi itu sendiri terbagi menjadi dua yaitu toleransi agama dan toleransi sosial. Toleransi agama menyangkut tentang keyakinan atau akidah, loyalitas dan keyakinan agama melahirkan dogma-doga yang kebenaranya tidak dapat diganggu gugat. Toleransi sosial atau toleransi kemasyarakatan mengenai hidup dalam masyarakat yang beranekaragam ras, tradisi, dan suku bangsa (Soraya, 2013). Toleransi perlu dimiliki oleh setiap manusia, guna terciptanya kedamaian sosial yang harmoni dan juga bebas dari rasisme (Killen et al., 2011). Dalam hal ini menunjukkan bahwa mengajarkan toleransi sejak dini sangatlah penting, meningat sejak awal masa kanak-kanak, anak dibombardir oleh berbagai pesan yang saling bertentangan baik itu positif maupun negatif tentang individu berdasarkan jenis kelamin, ras etnis dan budaya. Oleh karenanya mengenalkan kesetaraan, toleransi dan keadilan pada anak sangat diperlukan, agar anak dapat memahami perbedaan tersebut (Killen et al., 2011).

Toleransi berarti anak memperlakukan orang lain dengan baik dan penuh pengertian, menentang permusuhan, kekejaman, kefanatikan serta menghargai orang lain berdasarkan karakter mereka (Borba 2008). Pada anak usia dini toleransi mengacu pada kesadaran anak-anak yang sedang berkembang di dalamnya hubungan dengan orang lain, dan kemampuan untuk menerima penampilan dan perilaku yang berbeda dengan diri anak (Zakin, 2012). Penelitian yang dilakukan oleh Masko (2005) menunjukkan bahwa anak usia dini sadar terhadap perbedaan seperti warna kulit dan fisik, tetapi belum memperhatikan untuk itu. Oleh karena itu, anak-anak perlu dibantu untuk memahami perbedaan dan keragaman, sehingga mereka dapat memiliki toleransi terhadap orang lain daripada menghakimi dan melakukan bullying terhadap orang yang berbeda dari mereka sendiri. Sekolah merupakan tempat dimana anak-anak mempelajari keragaman dan kemampuan dalam menerima perbedaan, hal tersebut berkaitan juga dengan apa yang disampaikan guru 
(Smith, 2012). Maka dari itu selain lingkungan keluarga, lingkungan sekolah juga perlu dalam mengajarkan anak tentang pendidikan karakter (Prasanti \& Fitriani, 2018). Dalam hal ini termasuk karakter toleransi yang juga penting diajarkan pada anak usia dini.

Namun dalam mengajarkan toleransi pada anak, perlu dilakukan dengan hati-hati, mengingat bahwa anak berada pada fase pra-operasional konkret (Santrock, 2014). Mengingat hal tersebut, mengajarkan toleransi pada anak perlu disederhanakan agar dapat diterima oleh anak, salah satunya guru dapat memperkenalkan toleransi pada anak dengan melalui kegiatan bercerita. Musbikin (2010: 248) mengungkapkan bahwa cerita yang diberikan oleh guru kepada anak akan memberikan rangsangan kepada salah satu bagian otak yang terletak di daerah pelipus (lobus temporal), yaitu good spot, hal tersebut berfungsi secara sempurna untuk memberikan bisikan-bisikan suara hati yang senantiasa mendorong ke arah tindakan yang mulia. Adapun cerita yang disampaikan dapat berupa cerita rakyat yang memiliki unsur untuk mempengaruhi tingkah laku, terutama perilaku sosial anak (Coe et all, 2005). Cerita rakyat kaya akan pesan-pesan sosial dan budaya yang memungkinkan anak untuk mengembangkan konsep terkait dengan situasi sosial dan dunia sekitar mereka (Agbenyega et al., 2017).

Untuk menyampaikan pesan-pesan moral atau karakter melalui cerita, diperlukan media sebagai alat yang membantu membuat hal-hal abstrak menjadi lebih konkret di mata anak, salah satunya yakni dengan big book. Big book merupakan salah satu jenis dari picture book dapat memberi pelajaran bagi siswa agar memiliki kesadaran dalam bersikap dan bertingkah laku dengan baik melalui keteladanan tokoh dalam cerita (Turan \& Ulutas, 2016). Big book merupakan media potensial dalam pengembangan karakter, hal ini karena big book biasanya memperkenalkan suatu karakter dan bagaimana mengembangkan karakter (Rausch, 2011).

Pada penggunaannya big book dapat membantu pesan-pesan toleransi menjadi lebih konkret sehingga mudah diterima anak. Sejalan dengan hal tersebut, Tsai (2012) dalam studinya mengungkapkan bahwa Big book yang juga termasuk picture book dapat digunakan dalam mengembangan sosial, emosi dan moral anak, serta melatih anak mengekspresikan perasaan yang terdapat pada cerita. Hal ini karena buku-buku tersebut sering ditangani dengan subjek yang menjadi perhatian atau penting bagi anak (Kendall, 2010). Ukuran big book yang besar memugkinkan keseluruhan anak untuk melihat dan bereaksi terhadap halaman cetak saat dibaca selain itu partisipasi anak dapat terdorong (Stricland et al 2004; Loughrey, 2006; (Ma \& Wei, 2015)

Penelitian mengenai big book telah banyak dilakukan salah satunya terkait dengan pengembangan nilai sosial dan moral (Lukens 2003; Li, 2015; Gambrell \& Sokolski, 2016;). Selain itu, penelitian lainnya yang dilakukan oleh Kiromi, I.H., Fauziah, (2016) terkait dengan penggunaan media big book dalam menerapkan karakter pada anak, hasil penelitian menunjukkan bahwa media big book dapat digunakan dalam penerapan karakter kejujuran, karakter disiplin dan juga karakter peduli lingkungan. Namun dari beberapa studi tersebut belum ada yang meninjau karakter toleransi, sehingga hal tersebut perlu dikembangkan.

Penanaman karakter toleransi melalui big book tentunya perlu memilah jenis cerita yang relevan. Dalam hal ini cerita rakyat merupakan salah satu cerita yang dapat digunakan dalam menanamkan toleransi. Cerita rakyat sangat tepat diberikan pada anak usia dini mengingat bahwa cerita rakyat memuat pesan moral yang mencerminkan kehidupan dalam masyarakat, cerita rakyat mengandung ajaran baik melalui perilaku baik pada setiap penokohan cerita serta mengajarkan dampak dari perbuatan tidak baik. Cerita rakyat berfungsi sebagai media pengungkapan perilaku terkait nilai-nilai kehidupan yang melekat dalam kehidupan masyarakat (Bunanta, 1998 : 21). Hal tersebut diperkuat dengan pendapat Kose (2015 : 301) yang mengungkapkan bahwa isi sebuah cerita perlu mengandung budaya serta nilai edukatif yang memuat informasi-informasi penting serta mudah dipahami siswa. 
Berbagai penelitian terkait cerita rakyat telah banyak dilakukan, salah satunyya studi yang dilakukan Agbenyega et al., (2017) mengeksplorasi cerita rakyat Afrika dalam perkembangan pemikiran reflektif anak mengenai kehidupan sosial. Temuan menunjukkan bahwa folklore berkontribusi besar dalam pembelajaran dan pengembangan anak yang terkait dengan imajinasi, pembinaan konsep pemikiran dan dalam hubungan sosial. Sehubungan dengan hal tersebut, studi lainnya yang dilakukan Coe et al., (2005) menunjukkan bahwa cerita rakyat dapat memberi bimbingan moral, sosial yang baik agar dapat diterima secara luas, serta meyakinkan orang lain dalam berperilaku secara tertentu. Hal tersebut sesuai tahapan dengan penalaran moral anak, yang mana anak berada pada fase prakonfensional, sehingga orientasi anak berada pada hukuman dan ketaatan dan bertujuan untuk mempengaruhi perilaku anak termasuk juga dalam meningkatkan karakter anak. Adapun penelitian lainnya juga dilakukan oleh Ramdhani et al., (2019), penelitian menunjukkan bahwa cerita rakyat dapat digunakan khususnya pada pendidikan anak usia dini untuk meningkatkan karakter tanggung jawab, mandiri, jujur dan kerja sama.

Berdasarkan beberapa penelitian di atas bahwa penelitian terkait media big book, cerita rakyat maupun terkait pendidikan karakter telah dilakukan, tetapi dari beberapa penelitian di atas belum ada yang menggkaji mengenai efektifitas big book berbasis cerita rakyat dalam meningkatkan karakter toleransi anak. Oleh karena itu penelitian ini bertujuan untuk menguji efektivitas media big book berbasis cerita rakyat terhadap karakter toleransi anak. Cerita rakyat yang digunakan dalam penelitian ini merupakan cerita asal Jawa Barat dan memuat nilai-nilai toleransi.

\section{METODOLOGI}

Pengumpulan data dilakukan melalui observasi aktivitas atau kegiatan yang sedang berlangsung untuk melihat tingkat toleransi anak. Observasi dilakukan dengan menggunakan instrumen observasi karakter toleransi. Intrumen pada penelitian ini telah melalui proses validasi oleh para ahli. Validitas instrumen dalam penelitian ini menggunakan content validity. Pensekoran dalam penelitian ini menggunakan skala likert 1-4 yakni belum berkembang, mulai berkembang, berkembang sesuai harapan, dan berkembang sangat baik. Adapun item yang dinilai yakni :

Tabel 1. Item yang dinilai

\begin{tabular}{cl}
\hline No. & \multicolumn{1}{c}{ Theme } \\
\hline 1 & Anak menghargai perbedaan fisik \\
2 & Anak menghargai perbedaan jenis kelamin \\
3 & Anak menghargai perbedaan agama \\
4 & $\begin{array}{l}\text { Anak menghargai perbedaan pendapat dengan } \\
\text { anak lain }\end{array}$ \\
5 & Anak membela teman yang tidak bersalah \\
6 & Anak mampu bekerja sama dengan anak lain \\
\hline
\end{tabular}

Penelitian ini adalah eksperiment dengan disain pretest-postest control group, yang melibatkan kelompok kontrol dan kelompok eksperimen. Penelitian ini dilakukan di TK Negeri Manonjaya Jawa Barat terdiri dari 105 populasi diantaranya memiliki budaya, agama serta latar belakang yang berbeda. Sampel dalam penelitian ini dipilih berdasarkan teknik non random purposive sampling, yang terdiri dari 30 anak usia 5-6 tahun diantaranya 15 sebagai kelompok kontrol dan 15 kelompok eksperimen. Pada pelaksanaannya penelitian ini menggunakan non equivalent control group design, dalam hal ini kelompok eksperimen diberikan perlakuan dengan menggunakan media big book berbasis cerita rakyat sementara kelompok kontrol menggunakan buku cerita biasa. 
Tabel 2. non equivalent control group design

\begin{tabular}{|c|c|}
\hline \multirow{2}{*}{$\begin{array}{l}\text { Experiment } \\
\text { Group }\end{array}$} & $\begin{array}{l}\text { Learning with big book Posttest } \\
\text { based on folklore }\end{array}$ \\
\hline & $\mathrm{O} 1 \rightarrow \mathrm{X} 1 \rightarrow \mathrm{O} 2$ \\
\hline \multirow{2}{*}{ Control Group } & $\begin{array}{lll}\text { Pretest } & \text { Convensional learning } & \text { Posttest }\end{array}$ \\
\hline & $\mathrm{O} 3 \rightarrow \mathrm{X} 2 \rightarrow \mathrm{O} 4$ \\
\hline
\end{tabular}

Keterangan :

O1 : Perlakuan awal kelompok eksperimen (untuk melihat karakter toleransi sebelum penggunaan media big book berbasis cerita rakyat)

O2 : Perlakuan awal kelompok eksperimen (untuk melihat karakter dan toleransi setelah penggunaan media big book berbasis cerita rakyat)

X1 : Pembelajaran menggunakan media big book berbasis cerita rakyat

X2 : Pembelajaran konvensional

O3 : Perlakuan awal kelompok kontrol (untuk melihat karakter toleransi)

O4 : Perlakuan awal kelompok kontrol (untuk melihat karakter toleransi)

Analisis data pada penelitian ini menggunakan beberapa pengujian yakni: uji normalitas, uji homogenitas dan uji t-test dengan taraf signifikansi 0,05, analisis data dilakukan melalui bantuan SPSS 15.0. Adapun hipotesis pada penelitian ini adalah sebagai berikut:

H0 : Tidak ada perbedaan yang signifikan antara kelompok eksperimen dan kelompok kontrol ditinjau dari karakter toleransi

Ha : Terdapat perbedaan yang signifikan antara kelompok eksperimen dan kelompok kontrol ditinjau dari karakter toleransi

\section{HASIL DAN PEMBAHASAN}

\section{Hasil Penelitian}

Pada penelitian ini peneliti menggunakan dua kelompok, yang terdiri dari kelompok kontrol dan kelompok eksperimen, adapun subjek yang digunakan yakni kelompok kontrol sebanyak 15 anak dan kelompok eksperimen 15 anak. Masing-masing diberikan pretest dan postest, sementara itu perbedaan pada kedua kelompok tersebut bahwa kelompok eksperimen diberikan perlakuan menggunakan media big book dan kelompok kontrol diberikan perlakuan menggunakan buku cerita dengan ukuran biasa. Adapun hasil pengujian diuraikan sebagai berikut.

\section{Hasil Uji Normalitas dan Homogenitas Data}

Uji normalitas dilakukan untuk menguji asumsi bahwa data membentuk distribusi normal baik pada kelompok eksperimen maupun pada kelompok kontrol. Sementara uji homogenitas dilakukan untuk mengetahui apakah data yang diteliti berasal dari populasi yang homogen. Berikut hasil uji normalitas pretest karakter peduli sosial pada kelompok kontol dan kelompok eksperimen:

Tabel 3. Uji normalitas toleransi

\begin{tabular}{|cc|c|c|c|}
\hline & Group & \multicolumn{4}{|c|}{ Kolmogorov-Smirnov(a) } \\
& & Statistic & Df & Sig. \\
\hline Pretest & Control &, 171 & 15 &, $200\left(^{*}\right)$ \\
& Experiment &, 118 & 15 &, $200\left(^{*}\right)$ \\
& & & & \\
\hline
\end{tabular}

94 | Jurnal Obsesi : Jurnal Pendidikan Anak Usia Dini, 4(1), 2020 
Tabel 3 menunjukan bahwa nilai sig kelompok kontrol yakni 0,200 >0,05 artinya data berdistribusi normal, begitu juga dengan kelompok eksperimen yang memperoleh nilai sig $0,20>0,05$ artinya data kelompok eksperimen juga berdistribusi normal.

Tabel 4. Uji normalitas postest karakter toleransi

\begin{tabular}{|cc|c|c|c|}
\hline \multirow{2}{*}{ Group } & \multicolumn{3}{|c|}{ Kolmogorov-Smirnov(a) } \\
\cline { 3 - 5 } & & Df & Sig. \\
\hline Posttes & Control &, 172 & 15 &, $200\left(^{*}\right)$ \\
& Experiment &, 193 & 15 &, 138 \\
\hline
\end{tabular}

Pada tabel 4 nilai postest menunjukan bahwa sig kelompok kontrol yakni 0,200 >0,05 artinya data berdistribusi normal, begitu juga dengan kelompok eksperimen yang memperoleh nilai sig 0,138 >0,05 artinya data kelompok eksperimen juga berdistribusi normal.

Tabel 5. Uji homogenitas pretes karakter toleransi

\begin{tabular}{|r|r|r|r|}
\hline Levene Statistic & df1 & df2 & \multicolumn{1}{c|}{ Sig. } \\
\hline 2,507 & 1 & 28 &, 125 \\
\hline
\end{tabular}

Tabel 5 dapat disimpulkan bahwa nilai sigifikansi yakni 0,125 > 0,05 artinya varians populasi berasal dari populasi yang homogen.

Tabel 6. Uji homogenitas postest karakter toleransi

\begin{tabular}{|c|c|c|c|}
\hline Levene Statistic & $\mathrm{df} 1$ & $\mathrm{df} 2$ & Sig. \\
\hline 2,827 & 1 & 28 &, 104 \\
\hline
\end{tabular}

Nilai sigifikansi yakni 0,104 >0,05 artinya varians populasi berasal dari populasi yang homogen.

Berdasarkan hasil pengujian normalitas dan homogenitas pada kelompok kontrol dan kelompok eksperimen, dapat dilihat bahwa seluruh data berdistribusi normal dan homogen. Pada sub sesi selanjutnya akan membahas mengenai hasil uji t-test.

\section{Hasil Uji t-test Kelompok Kontrol dan Eksperimen}

Untuk mengetahui t-test dari kelompok eksperimen dan kelompok kontrol dapat dilihat dari tabel berikut ini:

Tabel 7. Hasil uji paired t-test karakter toleransi kelompok kontrol

\begin{tabular}{|c|c|c|c|c|c|c|c|c|c|}
\hline & & \multicolumn{5}{|c|}{ Paired Differences } & \multirow[b]{3}{*}{$\mathrm{T}$} & \multirow[b]{3}{*}{ Df } & \multirow{3}{*}{$\begin{array}{l}\text { Sig. (2- } \\
\text { tailed) }\end{array}$} \\
\hline & & \multirow[b]{2}{*}{ Mean } & \multirow{2}{*}{$\begin{array}{l}\text { Std. } \\
\text { Deviati } \\
\text { on }\end{array}$} & \multirow{2}{*}{$\begin{array}{l}\text { Std. } \\
\text { Error } \\
\text { Mean }\end{array}$} & \multicolumn{2}{|c|}{$\begin{array}{l}\text { 95\% Confidence } \\
\text { Interval of the } \\
\text { Difference }\end{array}$} & & & \\
\hline & & & & & Upper & Lower & & & \\
\hline Pair 1 & $\begin{array}{l}\text { Pretest- } \\
\text { posttest }\end{array}$ & $-3,80000$ & 3,25576 & 84063 & $-5,60298$ & $-1,99702$ & $-4,520$ & 14 &, 000 \\
\hline
\end{tabular}


Berdasarkan data yang diperoleh pada pretest dan postest toleransi kelompok kontrol, nilai sigifikansi yakni 0,000 lebih kecil dari 0,05 dengan kata lain bahwa ada perbedaan yang signifikan antara pretest dan postest kelompok kontrol. Sementara perolehan data pretest dan postest kelompok eksperimen adalah sebagai berikut:

Tabel 8. Hasil uji paired t-test karakter toleransi kelompok eksperimen

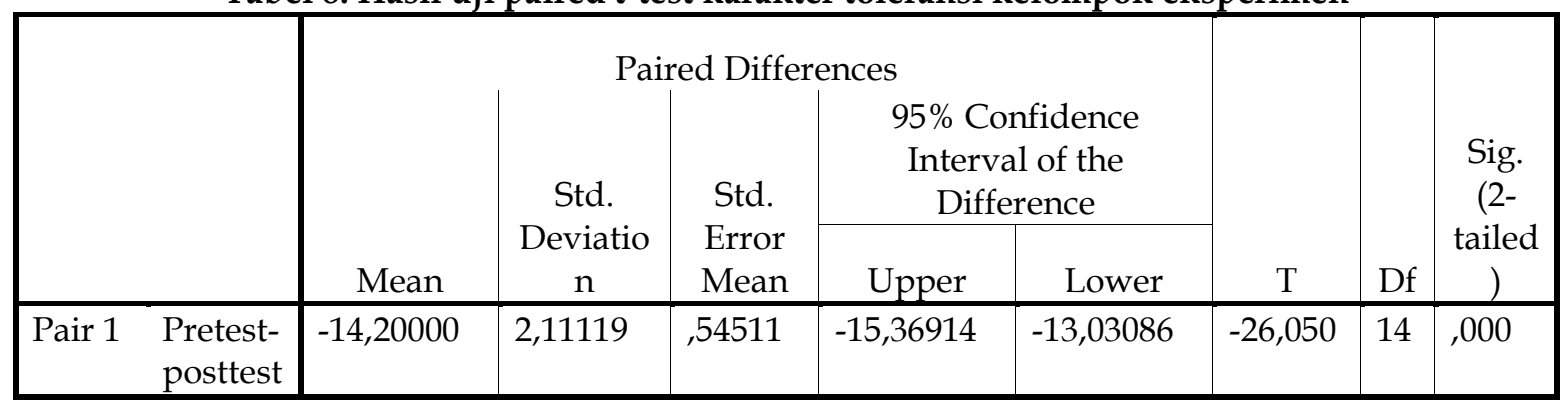

Tabel 8 menunjukkan bahwa nilai signifikansi karakter toleransi kelompok eksperimen yakni 0,000 kurang dari 0,05 hal tersebut menunjukkan terdapat perbedaan yang signifikan pretest dan postes karakter toleransi pada kelompok kontrol. Sementara itu, hasil pengujian dengan menggunakan independent $t$-test adalah sebagai berikut:

Tabel 9. Uji independen t-test pada post perlakuan kelompok eksperimen dan kontrol karakter toleransi

\begin{tabular}{|c|c|c|c|c|c|c|c|c|c|c|}
\hline & & \multicolumn{2}{|c|}{$\begin{array}{l}\text { Levene's } \\
\text { Test for } \\
\text { Equality } \\
\text { of } \\
\text { Variances }\end{array}$} & \multicolumn{7}{|c|}{ t-test for Equality of Means } \\
\hline & & \multirow[b]{2}{*}{$\mathrm{F}$} & \multirow[b]{2}{*}{ Sig } & \multirow[b]{2}{*}{$\mathrm{T}$} & \multirow[b]{2}{*}{ Df } & \multirow[b]{2}{*}{$\begin{array}{l}\text { Sig. (2- } \\
\text { tailed) }\end{array}$} & \multirow{2}{*}{$\begin{array}{c}\text { Mean } \\
\text { Differ } \\
\text { ence }\end{array}$} & \multirow[b]{2}{*}{$\begin{array}{l}\text { Std. } \\
\text { Error }\end{array}$} & \multicolumn{2}{|c|}{$\begin{array}{c}95 \% \\
\text { Confidence } \\
\text { Interval of } \\
\text { the } \\
\text { Difference }\end{array}$} \\
\hline & & & & & & & & & $\begin{array}{c}\text { Lowe } \\
\mathrm{r}\end{array}$ & $\begin{array}{c}\text { Upp } \\
\text { er }\end{array}$ \\
\hline $\begin{array}{l}\text { postest } \\
\text { toleransi }\end{array}$ & $\begin{array}{l}\text { Equal variances } \\
\text { assumed } \\
\text { Equal variances } \\
\text { not assumed }\end{array}$ & 2,82 & ,10 & $\begin{array}{r}- \\
5,16 \\
- \\
5,16\end{array}$ & $\begin{array}{r}28 \\
21,57\end{array}$ & $\begin{array}{l}, 00 \\
, 00\end{array}$ & $\begin{array}{l}-11,50 \\
-11,50\end{array}$ & $\begin{array}{l}2,22 \\
2,22\end{array}$ & $\begin{array}{l}-16,06 \\
-16,12\end{array}$ & $\begin{array}{l}-6,93 \\
-6,87\end{array}$ \\
\hline
\end{tabular}

\begin{tabular}{|ll|r|r|r|r|}
\hline & Kelas & $\mathrm{N}$ & Mean & $\begin{array}{c}\text { Std. } \\
\text { Deviation }\end{array}$ & Std. Error Mean \\
\hline $\begin{array}{l}\text { postest } \\
\text { toleran } \\
\text { si }\end{array}$ & Kontrol & 15 & 42,5333 & 7,58397 & 1,95817 \\
& Eksperimen & 15 & 54,0333 & 4,11212 & 1,06174 \\
\hline
\end{tabular}

Berdasarkan tabel di atas dapat dilihat bahwa untuk postest karakter toleransi antara kelompok eksperimen dan kelompok kontrol menunjukkan nilai signifikansi 0,000 kurang dari 0,05, maka dapat disimpulkan bahwa terdapat peningkatan karakter toleransi pada postest dengan menggunakan media big book berbasis cerita rakyat maupun dengan buku cerita berukuran kecil. Artinya bahwa baik media big book berbasis cerita rakyat sama efektifnya dengan media buku cerita berukuran kecil. 
Meskipun keduanya memiliki pengaruh dalam meningkatkan toleransi anak, tetapi perbedaan mean antara kelompok eksperimen dan kontrol dapat dilihat yakni untuk kelompok eksperimen 54,03 sementara pada kelompok kontrol 42,5. Hal tersebut menunjukkan bahwa pengguaan media big book berbasis cerita rakyat lebih efektif untuk meningkatkan toleransi anak dibandingkan dengan menggunakan media buku cerita berukuran kecil.

\section{Pembahasan}

Big book berbasis cerita rakyat efektif untuk meningkatkan karakter toleransi anak. Dilihat dari perolehan skor mean kelompok eksperimen yang lebih tinggi dari kelompok kontrol, sehingga dapat diasumsikan bahwa big book efektif untuk meningkatkan karakter toleransi anak. Hal tersebut dikarenakan media big book yang memiliki ukuran yang besar, bentuk gambar yang menarik serta warna yang mencolok sehingga mampu menarik perhatian anak-anak (Kiromi, I.H., Fauziah, 2016). Dengan menggunakan media bergambar, anak belajar secara simbolik yang berfungsi dalam memberikan kesenangan dan citra mental yang dapat membuat anak meniru perilaku pada gambar. penggunaan media yang interaktif seperti big book memungkinkan guru untuk menjelaskan, menyebarluaskan dan , memberikan pembelajaran dengan lebih mudah dan efektif daripada hanya bergantung pada kata-kata. (Adegbija \& Fakomogbon, 2012). Hal tersebut juga didukung oleh temuan Kendall, (2010) bahwa big book menawarkan ruang yang luas bagi anak untuk menghubungkannya dengan pengalaman, memberi anak kesempatan untuk menafsirkan teks dengan cara yang berarti. Ilustrasi pada big book membantu pembaca agar memahami cerita, selain itu ilustrasi juga menyediakan rincian pengaturan atau menunjukkan suasana hati dan nada buku (Colwell, 2013)

Cerita yang terdapat pada big book yakni cerita rakyat yang memuat nilai-nilai karakter toleransi. Cerita rakyat yang dibawakan adalah cerita yang berasal dari Jawa Barat berjudul "Si Buta dan Si Bungkuk". Cerita tersebut dimodifikasi agar bahasa yang digunakan sesuai untuk dibawakan pada anak usia 5-6 tahun. Cerita dikemas dengan menarik sesuai dengan indikator yang diangkat peneiti seperti menghargai perbedaan fisik, menghargai orang lain, bekerjasama, saling menyayangi, dengan demikian big book berbasis cerita rakyat sesuai untuk membantu dalam mengajarkan toleransi pada anak. Coe et al (2005) mengungkapkan bahwa folklore cerita yang disampaikan secara turun temurun yang mengandung unsur-unsur nilai kehidupan dan bertujuan untuk mempengaruhi moral dan tingkah laku anak, sehingga anak dapat menentukan nilai-nilai yang baik dan tidak baik, hal tersebut juga berlaku dalam penanaman karakter toleransi yang dimuat dalam folklore, dengan demikian anak terdoktrin untuk menghargai setiap perdebaan dengan orang lain. Selain itu melalui cerita rakyat siswa diajak untuk mengimplementasikan nilai-nilai moral yang dapat dicerna dengan positif dalam kehidupannya, sehingga nilai-nilai yang baik dapat dijadikan suri teladan sedangkan nilai-nilai yang buruk dapat dihindari siswa (Kose, 2015).

Lebih spesifik lagi bahwa big book berbasis cerita rakyat dapat membantu anak dalam belajar mengapresiasikan dan memahami perbedaan dengan orang lain baik dari fisik, agama, serta lebih memiliki empati terhadap orang lain. Sejalan dengan hal tersebut Zakin, (2012) mengungkapkan bahwa buku bergambar merupakan hal yang penting dalam mengenalkan toleransi pada anak, dalam hal ini guru membacakan buku cerita untuk mengajarkan perbedaan warna kulit pada anak. Dari pemaparan tersebut dapat dikatakan bahwa dalam penanaman nilai karakter terutama karakter toleransi dengan menggunakan media big book berbasis cerita rakyat dapat dijadikan salah satu masukan dalam mengembangkan nilai karakter di Taman Kanak-kanak. Dimana nilai-nilai yang ada dalam cerita rakyat yang dikemas kedalam media big book dapat meningkatkan karakter toleransi anak usia 5-6 tahun. 


\section{SIMPULAN}

Media pembelajaran big book berbasis cerita rakyat terbukti lebih efektif untuk meningkatkan karakter toleransi anak usia 5-6 tahun dibandingkan dengan menggunakan media buku biasa maupun pembelajaran konvensional. Anak yang mengikuti pembelajaran dengan media big book lebih mudah untuk dikondisikan mengingat bentuk big book yang besar sehingga dapat dilihat oleh keseluruhan anak. Selain itu cerita rakyat yang dimuat dalam big book membantu siswa untuk memahami perbedaan dengan orang lain.

\section{UCAPAN TERIMA KASIH}

Terima kasih penulis ucapakan kepada Universitas Negeri Yogyakarta, Kepala sekolah, guru dan murid-murid di TK Negeri Manonjaya, serta pihak-pihak yang telah membantu segala proses penelitian ini, sehingga memperoleh hasil penelitian yang bisa digunakan seabagai kajian keilmuan dalam Pendidikan Anak Usia Dini khususnya pada pembelajaran karakter.

\section{DAFTAR PUSTAKA}

Adegbija, M. V, \& Fakomogbon, M. A. (2012). Instructional Media In Teaching and Learning: A Nigerian Perspective. Global Media Journal, 6(2), 216-230. https:// doi.org/10.5789/6-2-114

Agbenyega, J. S., Tamakloe, D. E., Klibthong, S., Agbenyega, J. S., Tamakloe, D. E., \& Klibthong, S. (2017). Folklore epistemology: how does traditional folklore contribute to children 's thinking and concept development? International Journal of Early Years Education, 25(2), 1-15. https:// doi.org/10.1080/09669760.2017.1287062

Baklashova, T. A. (2015). The Effects of Education on Tolerance : Research of Students ' Social and Ethnic Attitudes. Mediterranean Journal of Social Sciences, 6(1), 335-340. https:// doi.org/10.5901/mjss.2015.v6n1s3p335

Cieri, R. L., Churchill, S. E., Franciscus, R. G., Tan, J., Cieri, R. L., Churchill, S. E., ... Hare, B. (2014). Craniofacial Feminization, Social Tolerance, and the Origins of Behavioral Modernity. Chicago Journals, 55(4), 419-443. https:/ / doi.org/10.1086/677209

Colwell, C. (2013). Children's Storybooks in the Elementary Music Classroom: A Description of Their Use by Orff-Schulwerk Teachers Children 's Storybooks in the Elementary by Orff-Schulwerk Teachers. Music Therapy \& Special Music Education, $5(2), 174-187$.

Kendall, S. (2010). Children 's Spiritual Development and Meaning Making [ 1 ] The Role of Picture Books in Children' s Spiritual Development and Meaning Making [ 1 ]. International Journal of Children's Spirituality, 4(1), 37-41. https:// doi.org/10.1080/1364436990040106

Killen, M., Rutland, A., \& Ruck, M. D. (2011). Social Policy Report, V25 \#4. Promoting Euqity, Tolerance, and Justice in Social Policy Report, V25 \#4. Promoting Euqity, Tolerance, and Justice in Childhood. Sharing Child and Youth Development Knowledge, 25(4). https:// doi.org/10.1002/j.2379-3988.2011.tb00069.x

Kiromi, I.H., Fauziah, P. Y. (2016). Jurnal Pendidikan dan Pemberdayaan Masyarakat. Jurnal Pendidikan Dan Pemberdayaan Masyarakat, 3(1), 48-59. https:// doi.org/10.21831/jppm.v3i1.5594

Li, M. (2015). A Study of Using Picture Storybooks to Increase Chinese Vocabulary of Primary School Students. The Open Cybernetics \& Systemics Journal, 9, 2886-2889. https:// doi.org/10.2174/1874110X01509012886

Loughrey, D. (2001). The Case for the Use of Big Books in the Early Years Classroom. Early Child Development and Care, 169(1), 85-96. https://doi.org/10.1080/0300443011690106

Ma, M., \& Wei, C. (2015). A comparative study of children' s concentration performance on picture books: age, gender, and media forms. Interactive Learning Environments, 
24(8), 1922-1937. https:// doi.org/10.1080/10494820.2015.1060505

Masko, A. L. (2005). '“ I Think About It All The Time "': A 12-Year-Old Girl ' s Internal Crisis With Racism and the Effects on Her Mental Health. The Urban Review, 37(4), 329-350. https://doi.org/10.1007/s11256-005-0014-2

Novikova, I. A., \& Novikov, A. L. (2013). Tolerance Types and Features of Intercultural Adaptation in International Students. Journal of Educational and Social Research, 3(7), 625-630. https://doi.org/10.5901/jesr.2013.v3n7p625

Pourghaz, A. (2016). Critical Thinking and Its Relationship with Social Tolerance among Students. The New Educational Review, 92. https:/ / doi.org/10.15804/tner.2016.45.3.07

Prasanti, D., \& Fitriani, D. R. (2018). Pembentukan Karakter Anak Usia Dini : Keluarga , Sekolah , Dan Komunitas? Jurnal Obsesi : Jurnal Pendidikan Anak Usia Dini, 2(1), 13-19. https://doi.org/10.31004/obsesi.v2i1.2

Ramdhani, S., Yuliastri, N. A., Sari, S. D., \& Hasriah, S. (2019). Penanaman Nilai-Nilai Karakter melalui Kegiatan Storytelling dengan Menggunakan Cerita Rakyat Sasak pada Anak Usia Dini. Jurnal Obsesi: Jurnal Pendidikan Anak Usia Dini, 3(1), 153. https://doi.org/10.31004/obsesi.v3i1.108

Rausch, A. S. (2011). Picture Story Books in Elementary School English Education : Revisiting the Mechanisms of Transmediation. 弘前大学教育学部紀要, 106, 15-22.

Soraya, S. (2013). Studi Eksperimen Penggunaan Media diversity Doll dan Media Gambar Sebagai Penanaman Sikap Toleransi Anak Usia 4-5 Tahun Di Raudhotul Athfal 02 Mangunsari Semarang. Indonesian Journal Of Early Childhood Education Studies, 2(2), 37-42. https:// doi.org/10.15294/ijeces.v2i2.9239

Turan, F., \& Ulutas, I. (2016). Using Storybooks as a Character Education Tools. Journal of Eduation and Practice, 7(15), 169-176.

Zakin, A. (2012). Childhood Education. Childhood Education, 88(1), 37-41. https://doi.org/10.1080/00094056.2012.643709 